\title{
Effect of cardiovascular risk factors and time of hospital presentation on mortality of maintenance hemodialysis patients presenting with acute pulmonary edema
}

Saki Hasegawa', Shintaro Nakano ${ }^{1 *}$, Jun Tanno', Shiro Iwanaga', Ritsushi Kato ${ }^{1}$, Toshihiro Muramatsu', Yusuke Watanabe², Hirokazu Okada², Takaaki Senbonmatsu', Hidetomo Nakamoto ${ }^{3}$ and Shigeyuki Nishimura ${ }^{1}$

\begin{abstract}
Background: Acute pulmonary edema (APE) has a poor prognosis in the general population. Mortality associated with APE in patients with end-stage renal disease (ESRD) is especially high, although specific predictors are not well understood. This study aimed to determine the potential predictive factors of outcome in patients with ESRD presenting with APE.

Methods: Sixty-eight patients with ESRD (mean age, $68.9 \pm 9.9$ years; males, 66.2\%; median duration of maintenance hemodialysis, 55.5 months) presenting with APE to a single tertiary medical center were retrospectively evaluated. The effects of patients' characteristics, cardiovascular risk factors, variables at hospital presentation, and clinical presentation patterns on all-cause mortality were evaluated.

Results: Throughout the observational period (median follow-up period, 575 days; range, 10-2546 days), 32 (47\%) patients died. In univariate analysis, older age, diabetes mellitus, peripheral artery or aortic disease, hypotension, atrial fibrillation rhythm, anemia, and hypoalbuminemia were associated with higher mortality, whereas hospital presentation from midnight to 8 am was associated with lower mortality. In multivariate analysis, age (hazard ratio $(H R)=1.05,95 \%$ confidential interval $(C l) 1.01-1.09, p=0.018)$, presence of peripheral artery or aortic disease $(H R=$ $3.36,95 \% \mathrm{Cl} 1.52-7.42, p=0.003)$, time of presentation from midnight to 8 am $(H R=0.40,95 \% \mathrm{Cl} 0.15-0.99, p=0$. 047), and atrial fibrillation rhythm at presentation ( $\mathrm{HR}=3.12,95 \% \mathrm{Cl} 1.04-9.13, p=0.044)$ were significantly independently associated with mortality.
\end{abstract}

Conclusions: Our findings indicate important predictive roles of the clinical presentation pattern specific to ESRD patients, as well as their characteristics, including cardiovascular risk factors.

Keywords: Pulmonary edema, End-stage renal disease, Dialysis, Clinical presentation

\section{Background}

The number of patients on maintenance hemodialysis suffering from end-stage renal disease (ESRD) is approximately 400,000 in the USA [1] and approximately 300,000 in Japan [2]. Cardiovascular disease accounts for $50 \%$ of death among these patients [3], with congestive heart failure comprising approximately $25 \%$ of death in Japan [2].

\footnotetext{
* Correspondence: snakano@saitama-med.ac.jp

'Department of Cardiovascular Medicine, Saitama Medical University International

Medical Center, 1397-1 Yamane, 350-1298 Hidaka, Saitama, Japan

Full list of author information is available at the end of the article
}

Acute pulmonary edema (APE), which is a common symptom of acute heart failure requiring hospital admission, is associated with considerable mortality $[4,5]$. This condition is accompanied by severe respiratory distress, audible crackles, and orthopnea and is verified by chest Xray [6]. In addition to respiratory support, initial treatment of APE aims to ameliorate preload and afterload [7]. In the general population, factors such as older age, hypotension, hyponatremia, and anemia at presentation are predictors of poor outcome in patients presenting with acute heart 
failure [8-11]. In patients with APE only, older age and hypotension predict mortality [5].

Despite high mortality (approximately $80 \%$ mortality at 5 years) and morbidity of APE $[12,13]$, evidence regarding APE in patients undergoing maintenance hemodialysis is lacking. Patients with ESRD on maintenance hemodialysis should be considered as different from the general population because they have different cardiovascular disease characteristics and responses to therapy [1,3]. Moreover, periodic hemodialysis therapy jeopardizes their preload to fluctuate non-physiologically. Therefore, risk stratification and therapeutic guidelines according to clinical presentation described in acute heart failure in the general population, such as the clinical scenario $[9,14]$, may not be applicable to this cohort.

Considering the distinct patho-physiology and high mortality, specific predictors in patients with ESRD on maintenance hemodialysis presenting with APE need to be investigated. This study aimed to determine the effects of demographics, non-cardiovascular and cardiovascular factors, and clinical presentation on all-cause mortality in patients on maintenance hemodialysis presenting with APE.

\section{Methods}

\section{Study design and population}

The medical records of 132 patients with ESRD on maintenance hemodialysis presenting with APE who required emergent admission were retrospectively reviewed. Patients were admitted to the Intensive Care Unit or Cardiac Care Unit in Saitama Medical University International Medical Center because of APE between April 2007 and October 2015. Maintenance hemodialysis was defined as performance of maintenance hemodialysis for 3 months or longer before admission. Patients were included if they showed pulmonary edema on an initial chest X-ray as determined by two observers (S.N. and S.H.). Patients who showed marginal X-ray findings with their clinical course that were inconsistent with APE were excluded after discussion with a third observer using clinical information. Figure 1 shows representative $\mathrm{X}$-rays of the included and excluded patients. Other exclusion criteria are shown in Fig. 2. Patients who required immediate invasive therapy for acute cardiovascular collapse (such as acute coronary syndrome) were excluded because the impact of sudden cardiac dysfunction and procedure-related outcomes may cancel the effects of the factors specifically related to maintenance hemodialysis or ESRD.

\section{Data collection}

Baseline demographics of patients, maintenance hemodialysis data, and coexisting or previous conditions were recorded. Hypertension was defined as current or previous treatment with anti-hypertensive medication. Diabetes mellitus was defined as treatment with anti-diabetic medication or hemoglobin A1c concentration of $\geq 6.5 \%$ [15]. Dyslipidemia was defined as treatment with anti-dyslipidemic medication or fasting serum concentration of low-density lipoprotein cholesterol $\geq 160 \mathrm{mg} / \mathrm{dl}$, high-density lipoprotein cholesterol $\leq 40 \mathrm{mg} / \mathrm{dl}$, or total cholesterol $\geq 240 \mathrm{mg} / \mathrm{dl}$ [16].

Malignancy, peripheral artery and aortic disease (e.g., aortic dissection and aortic aneurysm, either treated or untreated), previous myocardial infarction, and previous cerebral infarction and hemorrhage were recorded. Previous cardiovascular interventions, such as percutaneous coronary intervention, coronary artery bypass grafting,

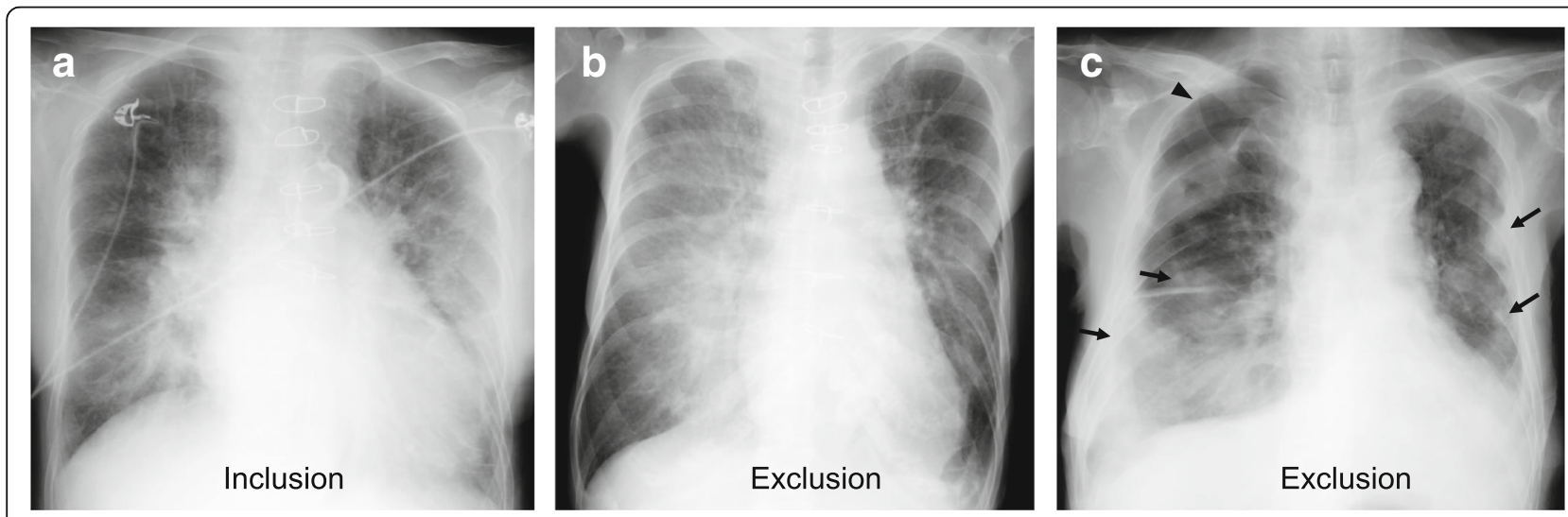

Fig. 1 Chest X-rays of included and excluded patients. a Included patient: A 58-year-old woman with X-ray findings typical of pulmonary edema. b Excluded patient: A 58-year-old woman with marginal X-ray findings showing right-side-dominant infiltration and modest cardiomegaly. Upon admission, this patient had hypotension (systolic blood pressure $70 \mathrm{mmHg}$ ), fever $\left(>38^{\circ}\right.$ ), and elevated levels of acute inflammatory biomarkers

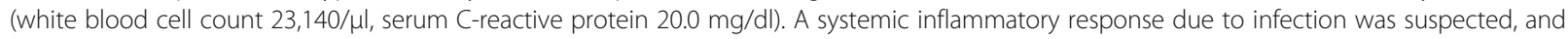
these abnormal parameters and X-ray findings were subsequently resolved with antibiotic therapy. c (excluded patient) An 81-year-old man with marginal X-ray findings showing abnormal pleural and pulmonary shadows (arrows) and pneumothorax (arrowhead). The patient had pleural and pulmonary metastases secondary to renal cancer 


\section{2 admissions due to acute pulmonary edema in patients on maintenance hemodialysis

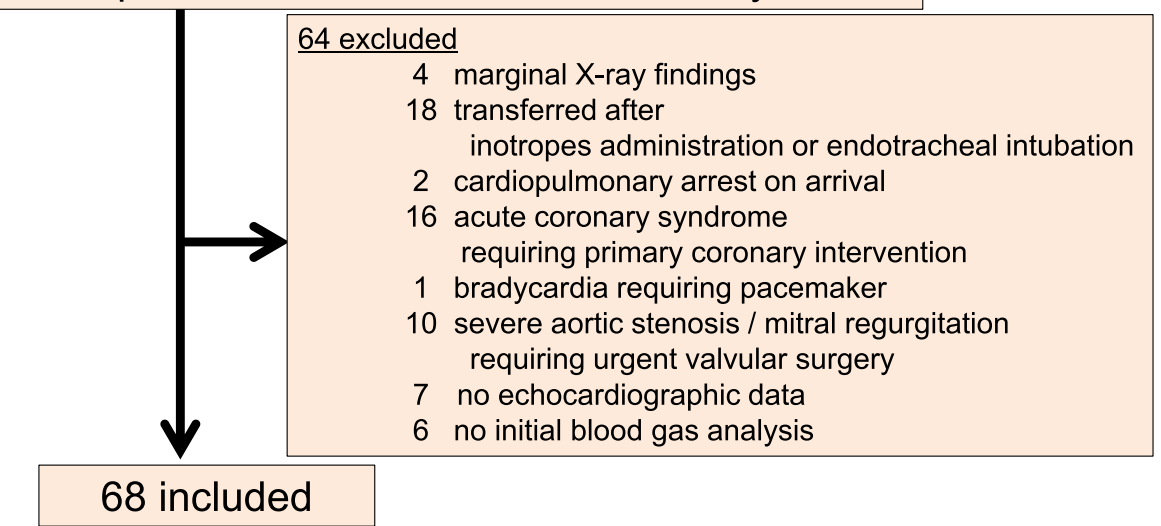

Fig. 2 Flow diagram of eligibility of patients

aortic surgery, percutaneous transluminal angioplasty or surgery for peripheral artery disease, valvular surgery, and pacemaker/cardio-defibrillator implantation, were recorded. Coronary artery anatomy collected from coronary angiography during the index or previous hospitalization was recorded. Medications that were administered prior to presentation were recorded.

For the prehospital course, the time elapsed from symptom (defined as dyspnea on exertion, paroxysmal nocturnal dyspnea, or orthopnea) onset to arrival was recorded, and the patients were divided into two groups ( $>72$ and $\leq 72 \mathrm{~h}$ ); in the $>72$-h group, their symptoms started before the last dialysis session. Hospital presentation time was recorded and divided into the following three groups: 8 am to $4 \mathrm{pm}, 4 \mathrm{pm}$ to midnight, and midnight to 8 am [17]. The 2-day interdialytic gap, body weight gain, and body weight gain rate were recorded.

Vital signs, arterial blood gases (before initiating specific respiratory support other than oxygen supplement alone), and laboratory findings at presentation were recorded. Echocardiographic and electrocardiographic variables were recorded.

Initial therapy within $48 \mathrm{~h}$ was recorded, and changes in subjective dyspnea and vital signs after the initial single hemodialysis session were evaluated.

\section{Outcome measures}

The associations between independent factors at presentation and all-cause death throughout the observation period were evaluated.

\section{Statistical analysis}

Continuous variables are expressed as the mean \pm standard deviation or median (first to third quartile) and categorical variables as number (\%). The Shapiro-Wilk test was performed for testing normal distribution. Univariate Cox proportional regression analyses were performed to identify the association between independent variables and all-cause death. Subsequently, multivariate Cox proportional regression analyses were performed to identify potential predictors of all-cause death. Because there are no established predictors of mortality in patients on maintenance hemodialysis presenting with APE, a multivariate model was constructed with independent variables using $p<0.05$ in univariate analysis. Kaplan-Meier analyses were performed to test the predictive value of independent variables for mortality with the log-rank test. All statistical analyses were performed using JMP Pro.11.2.0 (SAS Institute, Inc., Cary, USA).

\section{Results}

Baseline characteristics, variables of the prehospital course and at presentation, and initial therapy and response of patients

A flow diagram of the patients' eligibility is shown in Fig. 2. Sixty-eight patients were included in the final analysis. Baseline characteristics, data on maintenance hemodialysis, and coexisting or previous medical conditions are shown in Table 1. Peripheral artery disease was observed in 20 patients, including one with previous lower limb amputation. Aortic disease was observed in seven patients, including five with previous aortic surgery for their aortic dissection or aneurysm.

Coronary artery anatomy was only evaluated in 50 (73.5\%) patients. Medications and previous cardiovascular interventions are shown in Additional file 1: Tables S1 and S2.

Variables of the prehospital course and at presentation are shown in Table 2. Most patients were hypertensive at presentation. Their initial therapy within $48 \mathrm{~h}$ after 
Table 1 Baseline characteristics of patients and univariate Cox proportional analysis for all-cause death

\begin{tabular}{|c|c|c|c|}
\hline & Total $(n=68)$ & Hazard ratio & $p$ \\
\hline \multicolumn{4}{|l|}{ Demographics } \\
\hline Age (years) & $68.9 \pm 9.9$ & 1.06 & $0.003^{*}$ \\
\hline Male, $n(\%)$ & $45(66.2)$ & 2.03 & 0.08 \\
\hline Body mass index $\left(\mathrm{kg} / \mathrm{m}^{2}\right)$ & $21.1(19.1-24.3)$ & 0.95 & 0.30 \\
\hline \multicolumn{4}{|l|}{ Maintenance hemodialysis data } \\
\hline \multicolumn{4}{|l|}{ Etiology of kidney disease } \\
\hline Diabetic nephropathy, n (\%) & $44(64.7)$ & 1.16 & 0.70 \\
\hline Nephrosclerosis, $n(\%)$ & $6(8.8)$ & 1.74 & 0.33 \\
\hline Others, $n(\%)$ & $18(26.5)$ & 0.65 & 0.30 \\
\hline Duration of maintenance hemodialysis (months) & $55.5(27.3-85.5)$ & 1.00 & 0.95 \\
\hline Frequency (times/week) & $3(3-3)$ & NA & NA \\
\hline Each hemodialysis time (hours/day) & $4.0(4.0-4.0)$ & 1.05 & 0.88 \\
\hline \multicolumn{4}{|l|}{ Coexisting/previous conditions, $n(\%)$} \\
\hline Previous acute pulmonary edema & $24(35.3)$ & 1.09 & 0.82 \\
\hline Hypertension & $60(88.2)$ & 0.64 & 0.44 \\
\hline Diabetes mellitus & $52(76.5)$ & 2.47 & $0.04^{*}$ \\
\hline Dyslipidemia & $34(50.0)$ & 0.97 & 0.94 \\
\hline Current smoking & $10(14.7)$ & 0.98 & 0.97 \\
\hline Malignancy & $11(16.2)$ & 1.12 & 0.82 \\
\hline Peripheral artery or aortic disease & $21(30.9)$ & 2.98 & $0.005^{*}$ \\
\hline Previous myocardial infarction & $21(30.9)$ & 1.00 & 0.99 \\
\hline Previous cerebral infarction & $9(13.2)$ & 2.17 & 0.12 \\
\hline Previous cerebral hemorrhage & $4(5.9)$ & 1.08 & 0.91 \\
\hline \multicolumn{4}{|l|}{ Coronary anatomy $(n=50)$} \\
\hline Normal coronary artery, $n$ (\%) & $10(20.0)$ & 0.87 & 0.80 \\
\hline Left main trunk disease, $n(\%)$ & $3(6.0)$ & 0.95 & 0.96 \\
\hline Triple vessel disease, $n(\%)$ & $10(20.0)$ & 1.54 & 0.38 \\
\hline
\end{tabular}

Continuous variables are shown as the mean \pm SD or median (first to third quartile) and categorical variables as number (\%) $N A$ not analyzed ${ }^{*} p<0.05$

presentation and their responses are shown in Additional file 1: Table S3; $56(82.4 \%)$ patients required emergent hemodialysis, including continuous hemodialysis for expected hemodynamic instability. Most patients (86.4\%) demonstrated relief of subjective dyspnea and hypertension after initial renal replacement therapy.

\section{Univariate Cox proportional analyses for all-cause mortality}

The median follow-up period was 575 days (174-966: range 10-2546 days), and the total follow-up time was 135.4 years. Throughout the observational period, 32 (47\%) patients died from the following causes: myocardial infarction $(n=7)$, low-output circulatory failure $(n=6)$, acute pulmonary edema $(n=6)$, sudden death $(n=3)$, and other non-cardiovascular causes, such as malignancy $(n=3)$, liver failure $(n=3)$, pneumonia $(n=2)$, sepsis $(n=1)$, and an unknown cause $(n=1)$. Index in-hospital death was observed in six $(8.8 \%)$ patients. The potential cause of in-hospital death was cardiovascular events in all six patients, including low-output circulatory failure $(n=5)$ and acute myocardial infarction with shock $(n=1)$. However, most of these patients were complicated by sepsis or lower airway infection.

In univariate analysis, older age, the presence of diabetes mellitus, and peripheral artery disease or aortic disease were associated with higher all-cause mortality in the whole observational period. Lower systolic blood pressure, hematocrit, serum albumin levels, and AF rhythm at presentation were also significantly associated with higher mortality. The time of hospital presentation from midnight to 8 am was significantly associated with lower mortality (Tables 1 and 2). 
Table 2 Variables of the prehospital course and at hospital presentation, and univariate Cox proportional analysis for allcause death

\begin{tabular}{ll}
\hline Total $(n=68)$ & $\begin{array}{l}\text { Hazard } \\
\text { ratio }\end{array}$ \\
\hline
\end{tabular}

Prehospital course

$>72 \mathrm{~h}$ from onset to

$13(19.1)$

0.90

0.83

arrival, $n(\%)$

Time of hospital

presentation, $n(\%)$

- 8 am to 4 pm
- 4 pm to midnight
- Midnight to 8 am
2-day interdialytic gap, $n(\%)$
Body weight gain $(\mathrm{kg})$
Body weight gain rate $(\%)$
Vital signs
Systolic blood pressure
(mmHg)

$10(14.7)$

$22(32.4)$

$36(52.9)$

$37(54.4)$

$2.0(1.0-4.0)$

$4.1(1.4-6.0)$

$182(159-205)$

$94(72-115)$

$(\mathrm{mmHg})$

$$
\begin{aligned}
& \text { Heart rate (bpm) } \\
& \text { Respiratory rate (/min } \\
& \text { Saturation of periph } \\
& \text { oxygen (\%) } \\
& \text { Arterial blood gases } \\
& \mathrm{pH} \\
& \mathrm{pCO}_{2}(\mathrm{mmHg}) \\
& \mathrm{pO}_{2}(\mathrm{mmHg}) \\
& \mathrm{HCO}_{3-}(\mathrm{mmol} / \mathrm{l})
\end{aligned}
$$

Respiratory rate (/minute)

Saturation of peripheral

Echocardiographic variables (Teichholz method)

LVEDVI $\left(\mathrm{ml} / \mathrm{m}^{2}\right)$
LVESVI $\left(\mathrm{ml} / \mathrm{m}^{2}\right)$
Left ventricular ejection
fraction $(\%)$
Left ventricular mass index
$\left(\mathrm{g} / \mathrm{m}^{2}\right)$

$\begin{array}{lll}77.6(62.8-97.8) & 1.00 & 0.53 \\ 36.9(25.9-50.1) & 1.00 & 0.73 \\ 53(41.3-61) & 0.99 & 0.61 \\ 158(133-190.5) & 1.00 & 0.47\end{array}$

Electrocardiographic variables

Atrial fibrillation
rhythm, $n(\%)$
Artificially paced, $n(\%)$
Left ventricular
hypertrophy, $n(\%)$

QRS duration (ms)

Laboratory findings

White blood cell count
$\left(\times 10^{3} / \mu \mathrm{l}\right)$
Hematocrit (\%)

Platelet count $\left(\times 10^{3} / \mu \mathrm{l}\right)$

Blood urea nitrogen $(\mathrm{mg} / \mathrm{dl})$

$102(90-116) \quad 0.98 \quad 0.15$

$26(21-30) \quad 0.97 \quad 0.35$

$97(92-99) \quad 0.98 \quad 0.42$

$7.37(7.26-7.44) \quad 6.98 \quad 0.19$

\begin{tabular}{|c|c|c|c|}
\hline Creatinine $(\mathrm{mg} / \mathrm{dl})$ & $8.1 \pm 2.3$ & 0.88 & 0.08 \\
\hline $\begin{array}{l}\text { Aspartate aminotransferase } \\
(\mathrm{U} / \mathrm{I})\end{array}$ & $20(15-30)$ & 1.01 & 0.16 \\
\hline $\begin{array}{l}\text { Alanine aminotransferase } \\
(\mathrm{U} / \mathrm{I})\end{array}$ & $14(8-17)$ & 1.01 & 0.10 \\
\hline Albumin (g/dl) & $3.7 \pm 0.4$ & 0.28 & $0.007^{\dagger}$ \\
\hline Blood glucose $(\mathrm{mg} / \mathrm{dl})$ & $161(120.3-217.3)$ & 1.00 & 0.31 \\
\hline Sodium (mmol/l) & $139.1 \pm 3.1$ & 0.93 & 0.17 \\
\hline Potassium (mmol/l) & $4.8(4.3-5.4)$ & 1.04 & 0.84 \\
\hline Chloride $(\mathrm{mmol} / \mathrm{l})$ & $102.0 \pm 3.2$ & 0.95 & 0.31 \\
\hline Calcium (mg/dl), $n=61$ & $8.9 \pm 0.7$ & 0.98 & 0.96 \\
\hline Phosphate $(\mathrm{mg} / \mathrm{dl}), n=56$ & $5.0(3.6-5.8)$ & 1.06 & 0.61 \\
\hline C-reactive protein $(\mathrm{mg} / \mathrm{dl})$ & $0.53(0.15-1.85)$ & 1.01 & 0.89 \\
\hline
\end{tabular}

$38.8(34.5-50.6) \quad 0.99 \quad 0.26$

$83.4(61.4-97.5) \quad 1.00 \quad 0.72$

$22.1(19.6-24.6) \quad 1.03 \quad 0.60$

$\begin{array}{lll}10(14.7) & 3.34 & 0.01^{*} \\ 0(0) & \text { NA } & \text { NA } \\ 12(17.6) & 1.22 & 0.65 \\ 112(101.5-120) & 1.01 & 0.41 \\ & & \\ 10.2(7.7-12.4) & 0.97 & 0.56 \\ 34.4 \pm 5.3 & 0.92 & 0.03^{\dagger} \\ 213.2 \pm 69.2 & 0.99 & 0.07 \\ 47.0 \pm 16.1 & 1.00 & 0.66\end{array}$

Table 2 Variables of the prehospital course and at hospital presentation, and univariate Cox proportional analysis for allcause death (Continued)

Continuous variables are shown as the mean \pm SD or median (first to third quartile) and categorical variables as number (\%)

LVEDVI left ventricular end-diastolic volume index, LVESVI left ventricular endsystolic volume index, NA not analyzed

${ }^{*} p<0.05$ with a positive association, ${ }^{\dagger} p<0.05$ with a negative association

Potential predictors of all-cause mortality using multivariate Cox regression analysis

Variables that were significantly associated with allcause mortality were included in the multivariate regression model. Age $(p=0.018)$, presence of peripheral artery or aortic disease $(p=0.003)$, time of presentation from midnight to 8 am $(p=0.047)$, and AF rhythm at presentation $(p=0.044)$ were significantly independently associated with mortality (Table 3).

Kaplan-Meier analyses using potential predictors (Fig. 3) showed significantly higher all-cause mortality in patients with peripheral artery or aortic disease $(p=0.002)$ and with $\operatorname{AF}(p=0.003)$. Lower mortality was found in patients presenting from midnight to 8 am than in those presenting during the rest of the day $(p=0.007)$.

\section{Discussion}

The current study aimed to determine the potential predictors of mortality in patients with ESRD presenting with APE. We found that older age, the presence of peripheral or aortic disease, and AF rhythm at hospital presentation were independently associated with higher mortality, whereas the time of hospital presentation from midnight to 8 am was associated with lower mortality. These findings suggest an important role of the specific clinical presentation pattern in predicting mortality, as well as the importance of readily accessible acute data, including cardiovascular parameters. 
Table 3 Factors associated with all-cause death

\begin{tabular}{llll}
\hline & $\mathrm{HR}$ & $95 \% \mathrm{Cl}$ & $p$ \\
\hline Age & 1.05 & $1.01-1.09$ & $0.018^{*}$ \\
Diabetes mellitus & 1.70 & $0.65-5.45$ & 0.298 \\
Peripheral artery or aortic disease & 3.36 & $1.52-7.42$ & $0.003^{*}$ \\
Presentation from midnight to $8 \mathrm{am}$ & 0.40 & $0.15-0.99$ & $0.047^{\dagger}$ \\
Systolic blood pressure & 1.00 & $0.99-1.01$ & 0.956 \\
Atrial fibrillation rhythm & 3.12 & $1.04-9.13$ & $0.044^{*}$ \\
Hematocrit & 0.96 & $0.88-1.05$ & 0.414 \\
Albumin & 0.30 & $0.08-1.02$ & 0.053 \\
\hline
\end{tabular}

Cox proportional regression analyses were performed

$H R$ hazard ratio, $\mathrm{Cl}$ confidence interval

${ }^{*} p<0.05$ with a positive association, ${ }^{\dagger} p<0.05$ with a negative association

\section{Cardiac or non-cardiac APE in patients on maintenance hemodialysis}

Acute pulmonary edema may be caused by cardiac or non-cardiac etiology. Distinguishing cardiac from noncardiac APE using a single parameter, such as left ventricular contractility, is often difficult [18-20], especially in patients with ESRD whose fluid status is susceptible to excessive sodium and water intake. In these patients, underlying abnormal cardiac function is common because of volume overload (e.g., anemia, arteriovenous fistulas, and dialysis therapy per se), leading to left ventricular dilatation, or pressure overload (e.g., hypertension and atherosclerosis), leading to left ventricular hypertrophy and potential relative myocardial ischemia [3]. We speculate that their potential cardiovascular pathology may directly or indirectly lead to the development of APE. Therefore, comprehensive assessment of cardiovascular information, including previous or coexisting cardiovascular disease, and echocardiographic and electrocardiographic findings as candidate contributors of APE may be reasonable, rather than distinguishing cardiac from non-cardiac etiology.

\section{Effect of comorbidities and cardiac function}

Some studies focused on acute heart failure or pulmonary edema in patients with ESRD. We found that older age was significantly associated with mortality, which is consistent with previous studies $[12,21]$.

In our study, some conventional cardiovascular risk factors in the general population, such as coexisting dyslipidemia, hypertension, or obesity, were not associated with mortality. This finding may be partly explained by the reverse epidemiology in which these factors may play protective roles in under-nutrition [22]. In contrast, in our study, diabetes mellitus was associated with mortality in univariate analysis. Diabetes mellitus and coexisting macroand microvascular diseases are associated with a poor prognosis in patients on maintenance hemodialysis [12, 23-25]. We also found that the presence of peripheral artery or aortic disease was a strong predictor of mortality.

We found that AF rhythm at presentation was associated with mortality. Previous studies have reported an association between AF and all-cause mortality in patients with ESRD $[21,26]$. Interestingly, as demonstrated in our study, the association of AF with poor outcome was reported to be superior to that of left ventricular ejection fraction in patients with ESRD [21]. In our study, the median heart rate and duration of maintenance hemodialysis were comparable between patients with and without AF. Although the exact mechanism of a worse outcome associated with AF is unclear, potential acceleration of atrial remodeling caused by hemodialytic therapy and a high prevalence of embolic or bleeding events [21, 27] have been reported to be involved in high mortality.

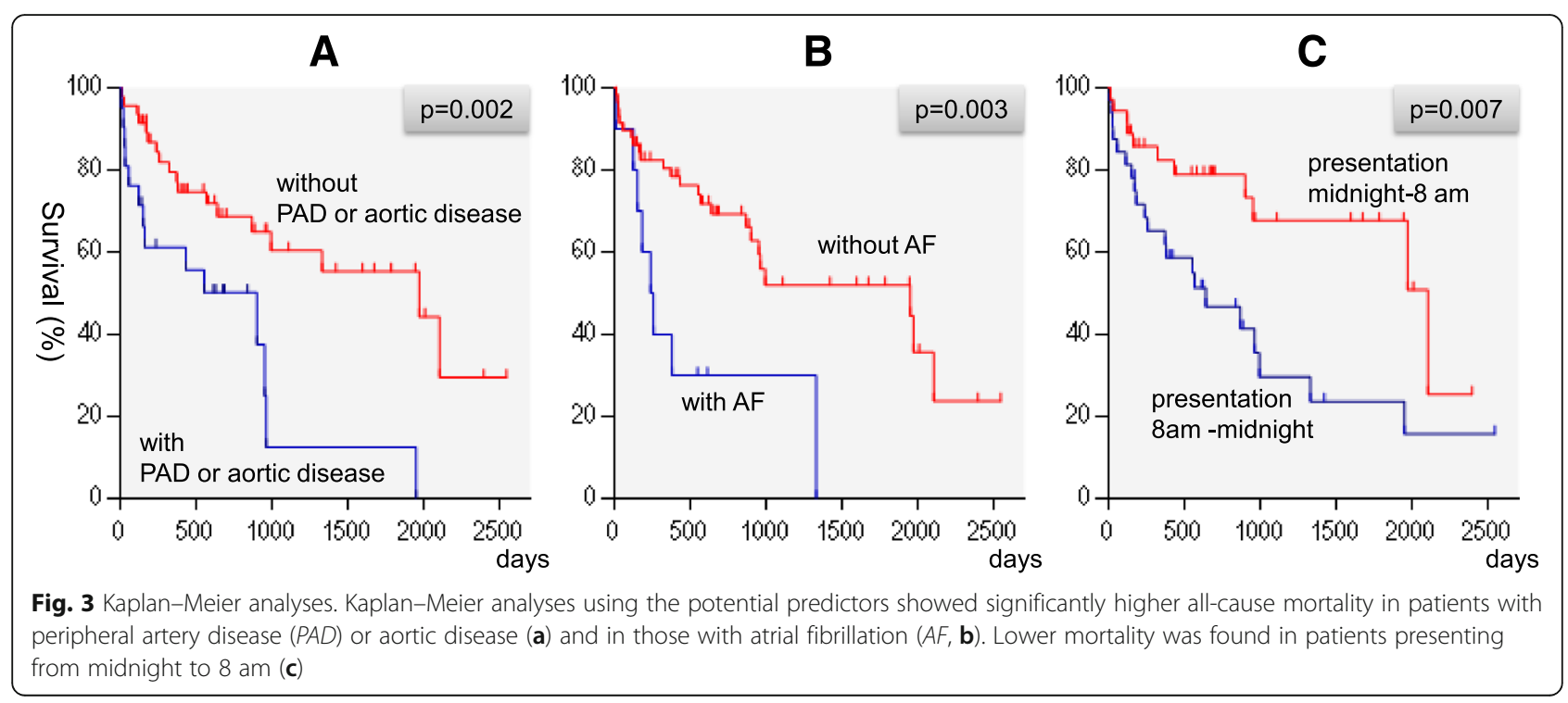


We also found that none of the acid-base parameters was associated with mortality. The acid-base imbalance observed in our cohort was mild (median pH, 7.37) and had little effect on outcome in patients with ESRD who are commonly exposed to mild acidosis [28].

\section{Effect of the clinical presentation pattern}

In patients undergoing maintenance hemodialysis, a substantial amount of fluid is retained in interdialytic period and quickly removed at hemodialysis treatment. This leads to non-physiological fluctuation of preload. Fluid retention is the main cause of emergent hospitalization in patients undergoing maintenance hemodialysis and is associated with mortality [13, 18]. However, greater weight gain or a 2-day gap after the last hemodialysis session was not associated with mortality in our study.

We found that hospital presentation from midnight to 8 am was significantly associated with lower mortality. The association between nighttime presentation and outcomes in general populations of patients with acute heart failure has not been determined [29, 30]. The definition of nighttime presentation varies among studies; in the current study, we recognized nighttime as the time from midnight to 8 am to eliminate the evening time when many patients were still awake. The concept of circadian fluid shift may partly explain this finding. Upon lying down at night, fluid that is accumulated during the daytime redistributes rostrally by gravity, resulting in fluid shift to the lungs, as well as the upper airway [31]. We speculate that APE developing at night may simply result from a fluid shift due to volume overload, whereas APE developing during the daytime might be attributable to underlying factors other than simple volume overload, such as an altered cardiovascular condition. Additionally, the potential presence of obstructive sleep apnea, which is a prevalent condition in patients with ESRD (50-70\%) [32], should be considered as a contributing factor to the better prognosis in patients who presented at night, although our study lacks polysomnographic data. In patients with concurrent ESRD and obstructive sleep apnea, rostral overnight fluid shift is associated with the severity of obstructive sleep apnea [33], possibly via an increase in the jugular vein volume and pharyngeal water content [34]. Hence, nighttime rostral fluid shift, which may lead to acute pulmonary edema, may be enhanced by obstructive sleep apnea. From a therapeutic viewpoint, rostral fluid shift resulting from fluid overload can be corrected by a single emergent hemodialysis session. Moreover, positive airway pressure, which was performed as initial respiratory management in some of our patients (Additional file 1: Table S3), might have helped to alleviate symptoms in patients with obstructive sleep apnea by unloading the inspiratory muscles and left ventricular afterload [35].
Interestingly, patients presenting at night had a higher median systolic blood pressure than did those presenting during the rest of the day. Elevated systolic blood pressure at presentation, possibly related to increased filling pressure and sympathetic hyperactivity, may favorably respond to pharmacological therapy, such as vasodilators, and is associated with lower mortality $[9,11]$. In the majority of our patients who presented at night, relief of dyspnea and hypertension was observed after a single emergent hemodialysis session. We speculate that these characteristic initial therapeutic strategies and their responses may be a reflection of the hemodynamics and neurohormonal responses that are specific to patients with ESRD.

The effect of delay from symptom onset to presentation has been discussed for general heart failure [36-40]. In our study, a delay in presenting to the hospital $(>72 \mathrm{~h}$ after initial symptoms) was not associated with mortality. We consider that because of the meticulous titration of the fluid balance at regular clinic visits, prolonged symptoms may be less common in patients with ESRD than in the general population. This situation indicates that the role of a delay in presentation is less meaningful in patients with ESRD than in the general population.

\section{Limitations}

This study has some limitations. First, it was an observational study conducted at a single tertiary center and included relatively small number of patients. A center-specific bias involving medical transfer systems should be considered as a potential social and infrastructural factor that contributed to the better prognosis of patients who presented at night. However, we included objective variables accessible at presentation and the clinical presentation pattern and found potential predictors of mortality from our longitudinal observation. Second, coronary artery anatomy, which may be an important predictor of mortality, was evaluated in only $73.5 \%$ of patients; therefore, we might have underestimated the implication of coronary artery anatomy. Clinically accessible parameters, such as echocardiographic or electrocardiographic variables, might have partially compensated for the insufficient coronary information.

\section{Conclusions}

In patients on maintenance hemodialysis presenting with APE, older age, the presence of peripheral artery or aortic disease, and AF rhythm at presentation were significantly associated with higher mortality, whereas the time of hospital presentation from midnight to 8 am was significantly associated with lower mortality. Our findings indicate important predictive roles of the clinical presentation pattern specific to patients with ESRD, as well as their characteristics, including cardiovascular risk factors. 


\section{Additional file}

Additional file 1: Table S1. Medications prior to admission. Table S2. Previous cardiovascular interventions. Table S3. Initial therapy and patients' response. (DOC $62 \mathrm{~kb}$ )

\section{Acknowledgements}

Not applicable

\section{Funding}

None to declare

\section{Availability of data and materials}

The datasets generated during and/or analyzed during the current study are available.

\section{Authors' contributions}

$\mathrm{SH}$ and $\mathrm{SNa}$ designed the study and drafted the manuscript. SH, YW, and $\mathrm{HO}$ collected the data. SH, SNa, JT, YW, HO, TS, and SNi analyzed and interpreted the data. SI, RK, TM, and HN revised the manuscript for intellectual content. $\mathrm{SNi}$ approved the final manuscript. All authors read and approved the final manuscript.

\section{Competing interests}

The authors declare that they have no competing interests.

\section{Consent for publication}

This manuscript contains no identifiable details from the corresponding author on reasonable request.

\section{Ethics approval}

The study was approved by the Institutional Review Board of Saitama Medical University International Medical Center (reference number: 15-280).

\section{Author details}

'Department of Cardiovascular Medicine, Saitama Medical University International Medical Center, 1397-1 Yamane, 350-1298 Hidaka, Saitama, Japan. 'Department of Nephrology, Saitama Medical University, Saitama, Japan. ${ }^{3}$ Department of General Internal Medicine, Saitama Medical University Hospital, Saitama, Japan.

Received: 6 September 2016 Accepted: 28 December 2016

Published online: 20 March 2017

\section{References}

1. Allon M. Evidence-based cardiology in hemodialysis patients. J Am Soc Nephrol. 2013:24(12):1934-43

2. Masakane I, Nakai S, Ogata S, Kimata N, Hanafusa N, Hamano T, Wakai K, Wada A, Nitta K. An overview of regular dialysis treatment in Japan (as of 31 December 2013). Ther Apher Dial. 2015;19(6):540-74

3. Fort J. Chronic renal failure: a cardiovascular risk factor. Kidney Int Suppl. 2005:99:S25-29.

4. Gheorghiade M, Zannad F, Sopko G, Klein L, Pina IL, Konstam MA, Massie BM, Roland E, Targum S, Collins SP, et al. Acute heart failure syndromes: current state and framework for future research. Circulation. 2005;112(25): 3958-68.

5. Gray A, Goodacre S, Nicholl J, Masson M, Sampson F, Elliott M, Crane S, Newby DE. The development of a simple risk score to predict early outcome in severe acute acidotic cardiogenic pulmonary edema: the 3CPO score. Circ Heart Fail. 2010;3(1):111-7.

6. Nieminen MS, Bohm M, Cowie MR, Drexler H, Filippatos GS, Jondeau G, Hasin Y, Lopez-Sendon J, Mebazaa A, Metra M, et al. Executive summary of the guidelines on the diagnosis and treatment of acute heart failure: the Task Force on Acute Heart Failure of the European Society of Cardiology. Eur Heart J. 2005:26(4):384-416.

7. Ellingsrud C, Agewall S. Morphine in the treatment of acute pulmonary oedema-why? Int J Cardiol. 2016;202:870-3.

8. Fonarow GC, Adams Jr KF, Abraham WT, Yancy CW, Boscardin WJ. Risk stratification for in-hospital mortality in acutely decompensated heart failure: classification and regression tree analysis. JAMA. 2005;293(5):572-80.
9. Gheorghiade M, Abraham WT, Albert NM, Greenberg BH, O'Connor CM, She L, Stough WG, Yancy CW, Young JB, Fonarow GC. Systolic blood pressure at admission, clinical characteristics, and outcomes in patients hospitalized with acute heart failure. JAMA. 2006;296(18):2217-26.

10. Klein L, O'Connor CM, Leimberger JD, Gattis-Stough W, Pina IL, Felker GM, Adams Jr KF, Califf RM, Gheorghiade M. Lower serum sodium is associated with increased short-term mortality in hospitalized patients with worsening heart failure: results from the Outcomes of a Prospective Trial of Intravenous Milrinone for Exacerbations of Chronic Heart Failure (OPTIME-CHF) study. Circulation. 2005:111(19):2454-60.

11. Felker GM, Leimberger JD, Califf RM, Cuffe MS, Massie BM, Adams Jr KF, Gheorghiade M, O'Connor CM. Risk stratification after hospitalization for decompensated heart failure. J Card Fail. 2004;10(6):460-6.

12. Banerjee D, Ma JZ, Collins AJ, Herzog CA. Long-term survival of incident hemodialysis patients who are hospitalized for congestive heart failure, pulmonary edema, or fluid overload. Clin J Am Soc Nephrol. 2007:2(6):1186-90.

13. Halle MP, Hertig A, Kengne AP, Ashuntantang G, Rondeau E, Ridel C. Acute pulmonary oedema in chronic dialysis patients admitted into an intensive care unit. Nephrol Dial Transplant. 2012;27(2):603-7.

14. Mebazaa A, Gheorghiade M, Pina IL, Harjola VP, Hollenberg SM, Follath F, Rhodes A, Plaisance $P$, Roland E, Nieminen $M$, et al. Practical recommendations for prehospital and early in-hospital management of patients presenting with acute heart failure syndromes. Crit Care Med. 2008; 36(1 Suppl):S129-139.

15. Gillett MJ. International Expert Committee report on the role of the A1c assay in the diagnosis of diabetes: diabetes care 2009; 32(7): 1327-1334. Clin Biochem Rev. 2009:30(4):197-200.

16. Executive Summary of The Third Report of The National Cholestero Education Program (NCEP) expert panel on detection, evaluation, and treatment of high blood cholesterol in adults (adult treatment panel III). JAMA. 2001:285(19):2486-2497.

17. Herzog CA, Littrell K, Arko C, Frederick PD, Blaney M. Clinical characteristics of dialysis patients with acute myocardial infarction in the United States: a collaborative project of the United States Renal Data System and the National Registry of Myocardial Infarction. Circulation. 2007;116(13):1465-72.

18. Kalantar-Zadeh $\mathrm{K}$, Regidor DL, Kovesdy CP, Van Wyck D, Bunnapradist S, Horwich TB, Fonarow GC. Fluid retention is associated with cardiovascular mortality in patients undergoing long-term hemodialysis. Circulation. 2009; 119(5):671-9.

19. Fonarow GC, Stough WG, Abraham WT, Albert NM, Gheorghiade M Greenberg BH, O'Connor CM, Sun JL, Yancy CW, Young JB. Characteristics, treatments, and outcomes of patients with preserved systolic function hospitalized for heart failure: a report from the OPTIMIZE-HF Registry. J Am Coll Cardiol. 2007:50(8):768-77.

20. McIntyre CW, Goldsmith DJ. Ischemic brain injury in hemodialysis patients: which is more dangerous, hypertension or intradialytic hypotension? Kidney Int. 2015;87(6):1109-15

21. Genovesi S, Vincenti A, Rossi E, Pogliani D, Acquistapace I, Stella A, Valsecchi MG. Atrial fibrillation and morbidity and mortality in a cohort of long-term hemodialysis patients. Am J Kidney Dis. 2008;51(2):255-62.

22. Kalantar-Zadeh K, Block G, Humphreys MH, Kopple JD. Reverse epidemiology of cardiovascular risk factors in maintenance dialysis patients. Kidney Int. 2003:63(3):793-808.

23. Chen SC, Chang JM, Hwang SJ, Tsai JC, Liu WC, Wang CS, Lin TH, Su HM, Chen HC. Ankle brachial index as a predictor for mortality in patients with chronic kidney disease and undergoing haemodialysis. Nephrology (Carlton). 2010;15(3):294-9.

24. Di Eusanio M, Schepens MA, Morshuis WJ, Dossche KM, Kazui T, Ohkura K, Washiyama N, Di Bartolomeo R, Pacini D, Pierangeli A. Separate grafts or en bloc anastomosis for arch vessels reimplantation to the aortic arch. Ann Thorac Surg. 2004;77(6):2021-8.

25. Kimmel PL, Varela MP, Peterson RA, Weihs KL, Simmens SJ, Alleyne S, Amarashinge A, Mishkin GJ, Cruz I, Veis JH. Interdialytic weight gain and survival in hemodialysis patients: effects of duration of ESRD and diabetes mellitus. Kidney Int. 2000;57(3):1141-51.

26. Mitsuma W, Matsubara T, Hatada K, Imai S, Saito N, Shimada H, Miyazaki S. Clinical characteristics of hemodialysis patients with atrial fibrillation: The RAKUEN (Registry of atrial fibrillation in chronic kidney disease under hemodialysis from Niigata) study. J Cardiol. 2016;68(2):148-55.

27. Genovesi S, Rossi E, Gallieni M, Stella A, Badiali F, Conte F, Pasquali S, Bertoli $\mathrm{S}$, Ondei $\mathrm{P}$, Bonforte $\mathrm{G}$, et al. Warfarin use, mortality, bleeding and stroke in 
haemodialysis patients with atrial fibrillation. Nephrol Dial Transplant. 2015; 30(3):491-8.

28. Oh MS, Uribarri J, Weinstein J, Schreiber M, Kamel KS, Kraut JA, Madias NE, Laski ME. What unique acid-base considerations exist in dialysis patients? Semin Dial. 2004;17(5):351-64.

29. Minami Y, Kajimoto K, Sato N, Yumino D, Mizuno M, Aokage T, Murai K, Munakata R, Asai K, Sakata Y, et al. Admission time, variability in clinical characteristics, and in-hospital outcomes in acute heart failure syndromes: findings from the ATTEND registry. Int J Cardiol. 2011;153(1):102-5.

30. Matsushita M, Shirakabe A, Hata N, Shinada T, Kobayashi N, Tomita K, Tsurumi M, Shimura T, Okazaki H, Yamamoto Y, et al. Association between the admission time and the clinical findings in patients with acute heart failure. J Cardiol. 2013;61(3):210-5.

31. Kalantar-Zadeh K, Abbott KC, Salahudeen AK, Kilpatrick RD, Horwich TB. Survival advantages of obesity in dialysis patients. Am J Clin Nutr. 2005; 81(3):543-54.

32. Roumelioti ME, Brown LK, Unruh ML. The relationship between volume overload in end-stage renal disease and obstructive sleep apnea. Semin Dial. 2015;28(5):508-13.

33. Elias RM, Bradley TD, Kasai T, Motwani SS, Chan CT. Rostral overnight fluid shift in end-stage renal disease: relationship with obstructive sleep apnea. Nephrol Dial Transplant. 2012;27(4):1569-73.

34. Elias RM, Chan CT, Paul N, Motwani SS, Kasai T, Gabriel JM, Spiller N, Bradley TD. Relationship of pharyngeal water content and jugular volume with severity of obstructive sleep apnea in renal failure. Nephrol Dial Transplant. 2013;28(4):937-44.

35. Naughton MT, Rahman MA, Hara K, Floras JS, Bradley TD. Effect of continuous positive airway pressure on intrathoracic and left ventricular transmural pressures in patients with congestive heart failure. Circulation. 1995;91(6):1725-31.

36. Gravely-Witte S, Jurgens CY, Tamim H, Grace SL. Length of delay in seeking medical care by patients with heart failure symptoms and the role of symptom-related factors: a narrative review. Eur J Heart Fail. 2010;12(10):1122-9.

37. Goldberg RJ, Goldberg JH, Pruell S, Yarzebski J, Lessard D, Spencer FA, Gore JM. Delays in seeking medical care in hospitalized patients with decompensated heart failure. Am J Med. 2008:121(3):212-8.

38. Shiraishi Y, Kohsaka S, Harada K, Sakai T, Takagi A, Miyamoto T, lida K, Tanimoto S, Fukuda K, Nagao K, et al. Time interval from symptom onset to hospital care in patients with acute heart failure: a report from the Tokyo Cardiac Care Unit Network Emergency Medical Service Database. PLoS One. 2015;10(11):e0142017.

39. De Luca L, Abraham WT, Fonarow GC, Gheorghiade M. Congestion in acute heart failure syndromes: importance of early recognition and treatment. Rev Cardiovasc Med. 2006;7(2):69-74.

40. Sethares KA, Chin E, Jurgens CY. Predictors of delay in heart failure patients and consequences for outcomes. Curr Heart Fail Rep. 2015;12(1):94-105.

\section{Submit your next manuscript to BioMed Central and we will help you at every step:}

- We accept pre-submission inquiries

- Our selector tool helps you to find the most relevant journal

- We provide round the clock customer support

- Convenient online submission

- Thorough peer review

- Inclusion in PubMed and all major indexing services

- Maximum visibility for your research

Submit your manuscript at www.biomedcentral.com/submit 